\title{
Hospital Discharge of Older Adults: A New Look at the Old, How Nurses Can Ease the Transition!
}

\author{
Malarvizhi M* \\ Sri Ramachandra College of Nursing, India
}

Submission: June 28, 2017; Published: July 05, 2017

*Corresponding author: Malarvizhi M, Lecturer, Sri Ramachandra College of Nursing, India, Email: malarvizhi23@gmail.com

\section{Opinion}

When an older adult is discharged from the hospital, she or he should have an individualized, comprehensive discharge plan to help prevent unnecessary complications and rehospitalization. But the large number of older adults who are hospitalized and their typically greater needs can make creating such a plan of challenge for clinicians. Clear communication among hospital personnel, patients, family members, case managers, and community caregivers (home health nurses) is essential.

According to Rud berg and colleagues, older patients in whom major losses in the ability to perform ADLs were noted during hospitalization-as a result of «a variety of cumulative and interactive effects, including acute illness, iatrogenic complications, and deconditioning» from decreased activitywere most likely to be admitted to a nursing home. Discharge planning has been described as being a part of daily nursing practice that poses significant challenges for nurses.

\section{Factors Affecting Discharge Planning}

\section{Hospital admission}

The percentage of patients on medical- surgical units who are 60 years old or older is quite high in most general hospitals, and they tend to have more needs at the time of discharge, it's important to improve discharge planning for this population. It is expected to increase by $78 \%$ by 2027 .

\section{Hospital readmission}

It leads to poor outcomes in older adults; therefore it's important to improve discharge planning and, by doing so, reduce readmission rates. It varies according to the type of illness, its severity, and the patient's medical history and compliance with treatment.

\section{Insurers}

Eg., Medicare and Medicare Advantage, often affect hospital discharge and length of stay by limiting reimbursement for hospitalization to a predetermined number of days for a specific diagnosis.

\section{Qualifying for Medicare Coverage for Skilled Care}

Because so many older adults require admission to a skilled nursing facility after being hospitalized, patients and family members should be made aware of the rules governing. The patients who have Medicare Part A be hospitalized for 3 or more consecutive days, not including the day of discharge; and need skilled care daily ans Medicare coverage ends after 100 days (Figure 1).

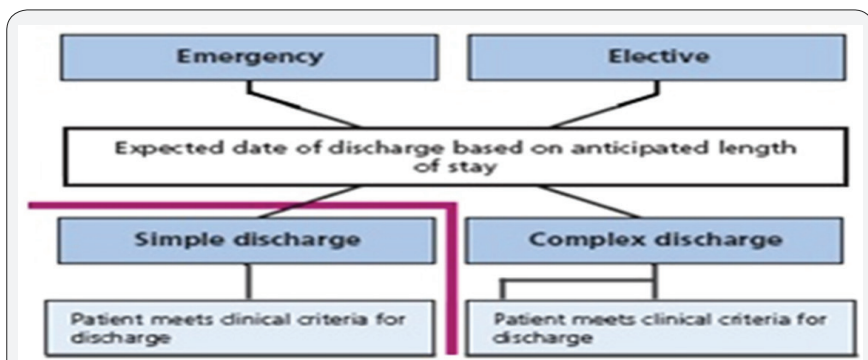

Figure 1: Key elements in discharge planning

\section{Models of Discharge Planning}

Bull MJ [1] professional partnership (PPP) model was the first of several models of discharge planning for older adults to appear in the literature. He compares the PPP model with four other models of discharge planning by indicating whether each calls for

A. A special inpatient unit for older adults.

B. The use of a team approach.

C. A goal of home placement.

D. An option for intermediate placement.

E. Attention to be given to specific strategies, such as communicating effectively, involving the family, preventing 
falls, assessing the home environment, and providing continuity of care.

\section{Acute Care for Elders Model (ACE)}

It is the most comprehensive model for discharge planning. Proponents of this model recommend conservative medical treatment and basic nursing care with an emphasis on client comfort and safety. Older adults admitted for an acute hospitalization often experience a decline in function is called as dysfunction syndrome. The nurses are encouraged to assess the pain with less sedation, increase mobility, and remove restraints and catheters. Retaining functional ability is necessary for successfully returning home [2].

\section{Nurses Improving Care for Healthy System Elders Model (Niche)}

This model sets benchmarks for evaluating continuous quality improvement in the evidence based care of older adults. It uses comprehensive discharge protocols. The objective is to lengthen time between rehospitalizations.

\section{Code of Control Model (COC)}

This considers the internal and external factors involved in health-related decision making by older adults and their families [3]. The main objective is to involve all concerned parties in decision making. This model encourages nurses to consider the context of their lives, beliefs about the illness and health; the caregivers for understanding information relevant to after care and promote client independence without compromising safety.

\section{Practical Improvement Cluster Model (Pic)}

It emphasis on the importance of communication when an older adult is placed in a transitional facility between an inpatient hospital stay and the eventual return to home. The main objective is to improve interagency reporting.

\section{Professional-Patient Partnership Model (PPP)}

It emphasizes on patient participation, family involvement and interdisciplinary collaboration in the discharge process [4]. The primary objective is to facilitate the effective discharge through teamwork. Outcomes include elders and caregivers who are better prepared to manage care, have greater information about care management and available services, have a better understanding of health status, are more satisfied with the care, and have fewer stays in the hospital if readmission is required.

\section{Implications for Practice}

A. A functional assessment that describes patients' abilities and limitations is essential in the first stage of getting to know patients in the discharge planning process.
B. As nurses take the lead in discharge planning.
C. Practitioners should use some measure of function to

get to know their patients and better inform the discharge process. This will also help ensure that they are providing the best care possible for patients.

\section{The Organization should have a Documented Discharge Process \\ Objective elements in Chapter I of Access , Assessment and continuity of care (AAC) (National Accreditation Board for Hospitals and Healthcare providers)}

A. The patient's discharge process is planned.

B. Policies and procedures exist for coordination of various departments and agencies involved in the discharge process (including medico-legal cases ).

C. Policies and procedures are in place for patients leaving against medical advice.

D. A discharge summary is given to all the patients leaving the organization (including patients leaving against medical advice).

\section{Organization should define the content of the discharge summary}
A. Discharge summary is provided to the patients at the time of discharge.

B. Discharge summary contains the reasons for admission, significant findings and diagnosis and the patient's condition at the time of discharge.

C. Discharge summary contains information regarding investigation results, any procedure performed, medication and other treatment given.

D. Discharge summary contains follow up advice, medication and other instructions in an understandable manner.

E. Discharge summary incorporates instructions about when and how to obtain urgent care.

F. In case of death the summary of the case also includes the cause of death. Patient records also contain a copy of the discharge / case summary.

\section{Discharge Planning (JCIA Standards)}

Discharge Planning is done at the time of admission so that a patient's needs even after discharge can be planned well ahead in time. It helps to improve the quality patient care and decreases readmissions due to lack of availability of vital equipment at home, after discharge.

\section{Components of discharge summary}
A. Reason for admission, diagnoses and comorbidities.
B. Significant physical and other findings. 
C. Diagnostic and therapeutic procedures performed.

D. Significant medications, including discharge medications.

E. Patient's condition/status at the time of discharge.

F. Follow-up instructions.

\section{Conclusion}

The discharge process varies from hospital to hospital, but most hospital systems should plan for and educate the patient and family much more thoroughly than they currently do. Hospital social workers and discharge nurses usually focus on the immediate discharge needs rather than on long-term goals and plans [5].
"If a geriatric care coordinator or an advanced practice nurse is not available through a hospital or in the community, the nurse is responsible for coordinating discharge planning".

\section{References}

1. Bull MJ, Roberts J (2001) Components of a proper hospital discharge for elders. J Adv Nurs 35(4): 571-581.

2. Bull MJ (1994) A discharge planning questionnaire for clinical practice. Appl Nurs Res 7(4): 193-199.

3. Chatterjee M (2004) Nurses to take over simple discharge. Nursing Times 100(2): 35.

4. Coats T (1998) When should FIM be measured following injury? London: Barts and The London NHS Trust, England.

5. http://www.apollodhaka.com/jci_hand_book.pdf

\section{Your next submission with Juniper Publishers will reach you the below assets}

- Quality Editorial service

- Swift Peer Review

- Reprints availability

- E-prints Service

- Manuscript Podcast for convenient understanding

- Global attainment for your research

- Manuscript accessibility in different formats ( Pdf, E-pub, Full Text, Audio)

- Unceasing customer service

Track the below URL for one-step submission https://juniperpublishers.com/online-submission.php 